\title{
Tolcapone: review of its pharmacology and use as adjunctive therapy in patients with Parkinson's disease
}

\section{Daniel D Truong}

The Parkinson's and Movement Disorder Institute, Fountain Valley, CA, USA
Correspondence: Daniel D Truong The Parkinson's and Movement Disorder Institute, 9940 Talbert Ave \# 204, Fountain Valley, CA 92708, USA

Tel + I 7143785062

Fax + I $7|4378506|$

Email dtruong@pmdi.org

\begin{abstract}
Levodopa has been the gold standard therapy for the motor symptoms of Parkinson's disease for more than three decades. Although it remains the most effective treatment, its long-term use is associated with motor fluctuations and dyskinesias that can be disabling for patients and difficult for physicians to manage medically. In the last 10 years, the catechol- $O$-methyltransferase (COMT) inhibitor tolcapone has been studied for its efficacy as an adjunctive treatment to levodopa plus a dopa decarboxylase inhibitor. Adjunctive therapy with tolcapone can significantly reduce the dose of levodopa required. Moreover, treatment with tolcapone significantly reduces wearing off and on-off periods in fluctuating patients and improves 'on' time in patients with stable disease. Tolcapone has assumed a new place in the arsenal of medications for Parkinson's disease. This paper reviews the pharmacology, safety and efficacy of tolcapone in patients with advanced Parkinson's disease. After some initial concerns about its safety, tolcapone has been shown to be safe if used and monitored according to guidelines regarding liver function. Tolcapone produces expected dopaminergic side effects, including headache, nausea, insomnia, as well as diarrhea; however, these side effects are generally mild and as a rule do not result in discontinuation of therapy.
\end{abstract}

Keywords: tolcapone, levodopa, Parkinson's disease, adjunctive therapy

\section{Introduction}

Levodopa has remained the gold standard treatment for the characteristic motor symptoms of Parkinson's disease (PD) for over 30 years. ${ }^{1}$ When administered with a dopamine decarboxylase inhibitor (DDCI), levodopa is still the most effective treatment for the cardinal motor symptoms of PD. ${ }^{2}$ Its effects are quick and it is well tolerated in the short to medium term. ${ }^{3}$ However, the long-term use of levodopa is limited by treatment-emergent motor fluctuations and dyskinesias that can be both challenging to manage and a significant source of disability for patients. The motor complications of levodopa are relatively common, occurring in about $10 \%$ of patients per year of treatment, so that by 5 years approximately $50 \%$ and by 10 years nearly $100 \%$ of patients have developed them. ${ }^{4}$ Concerns over the possibility of levodopainduced motor complications are especially relevant for younger patients with longer life expectancies.

The management of dyskinesias and motor fluctuations in PD patients treated with levodopa is challenging, but a number of guidelines and approaches are available. There is increasing evidence that dopamine agonists may be given in lieu of levodopa to manage motor symptoms of Parkinson's disease and to reduce complications. ${ }^{5}$ This approach would delay the need for levodopa and provide more continuous dopamine stimulation and therefore also delay the emergence of motor complications. For motor fluctuations specifically, options include increasing the dose of levodopa, using controlled release levodopa, adjunctive therapy with a dopamine agonist, or using 
subcutaneous apormorphine for rescue. ${ }^{5}$ In other cases it may be appropriate to add other adjunctive medications in an attempt to directly or indirectly offset motor fluctuations and/or to reduce the dose of levodopa required for symptom control.

Levodopa crosses the blood-brain barrier after oral administration, where it is decarboxylated by aromatic acid decarboxylase in the brain and periphery to produce dopamine. Levodopa is typically administered with a DDCI to reduce peripheral metabolism, reducing peripheral dopaminergic side effects (eg, postural hypotension, nausea), and increasing the amount of levodopa reaching the brain. When given in this way, $5 \%$ to $10 \%$ of levodopa reaches the brain. When decarboxylation is blocked, levodopa is metabolized predominantly to 3-O-methyldopa (3-OMD) by catechol$O$-methyltransferase (COMT), a selective and ubiquitous enzyme involved in the catabolism of levodopa. ${ }^{6}$ In the brain, COMT metabolizes levodopa to 3-OMD and dopamine to homovanillic acid. ${ }^{7}$ In the periphery, COMT is involved in the conversion of levodopa to 3-OMD. Based on this mechanism, it was posited that inhibiting COMT would result in less degradation of levodopa, and that, when administered with a DDCI, would increase levodopa bioavailability, CNS delivery, and continuity of dopamine stimulation. As a result the dose of levodopa required for therapeutic efficacy could be reduced, and this lower exposure to levodopa should delay or prevent motor complications.

Tolcapone is a potent, selective and reversible inhibitor of COMT in the periphery. ${ }^{8}$ It also exerts COMT inhibition in the brain, but the relevance of this effect to its efficacy in PD is less clear. ${ }^{9}$ Treatment with tolcapone has been shown to widen the therapeutic window for levodopa as expected, by reducing the doses needed for symptom control.

This review will provide an overview of the pharmacology of tolcapone as it relates to both efficacy and safety, and will then describe literature from clinical trials on the efficacy of tolcapone as adjunctive therapy in fluctuating and stable patients with PD.

\section{Pharmacology}

Tolcapone is typically administered in oral daily doses of $100 \mathrm{mg}$ or $200 \mathrm{mg}$ tid. The pharmacokinetics of the $100 \mathrm{mg}$ and $200 \mathrm{mg}$ doses show similar pharmacokinetics alone or in combination with levodopa plus a DDCI. ${ }^{10-12}$ In studies with healthy volunteers tolcapone shows linear pharmacokinetics over the 50 to $400 \mathrm{mg}$ dose range. ${ }^{13}$ The pharmacokinetics of tolcapone are the same in healthy volunteers as in patients with PD. ${ }^{14}$
After oral administration tolcapone is rapidly absorbed, with $60 \%$ bioavailability due to first pass metabolism. ${ }^{15}$ It reaches peak plasma concentration in 30 minutes to 2 hours. Tolcapone is highly plasma protein bound (more than $99.9 \%$ ) and thus has restricted distribution. ${ }^{13}$ Tolcapone undergoes extensive metabolism, primarily through glucuronidation to inactive $3-\mathrm{O}-\beta, \mathrm{D}$-glucuronic acid conjugate, with $0.5 \%$ of drug excreted unchanged. ${ }^{13,16}$

Tolcapone is eliminated fairly quickly, with an elimination half-life of 1.6 to 3.4 hours. ${ }^{17}$ The area under the tolcapone plasma-concentration time curve is dose-dependent, ${ }^{10}$ and its pharmacokinetics do not vary in the presence of food, after single vs repeated doses, or as a function of age. ${ }^{18}$ There is no evidence of pharmacodynamic tolerance after repeated dosing. ${ }^{19}$ There is little accumulation of the methylated metabolite of tolcapone after long-term administration.

Tolcapone reversibly decreases S-COMT activity in erythrocytes in a dose-dependent manner, with a rapid time to maximum inhibition of less than 2 hours. After oral doses of $100 \mathrm{mg}$ or $200 \mathrm{mg}$, maximum COMT inhibition is $72 \%$ and $80 \%$, respectively and returns to baseline approximately 18 hours after the $200 \mathrm{mg}$ dose. ${ }^{10,11}$ COMT inhibition with tolcapone leads to dose-dependent increases in the plasma half-life of levodopa as well as its area under the curve (AUC), ${ }^{10,11}$ without impacting $\mathrm{C}_{\max }$ or $\mathrm{T}_{\max }$. Factor et al ${ }^{20}$ showed that administration of tolcapone led to an $80 \%$ increase in the half-life of levodopa. Other studies have shown that tolcapone in doses of 100 or $200 \mathrm{mg}$ increase the bioavailability of levodopa by as much as 2.1 fold in both healthy volunteers and patients with Parkinson's disease. ${ }^{21}$ Consequently, levodopa levels are more continuous (less fluctuating), which should reduce the development of dyskinesias. ${ }^{22,23}$ Indeed, clinical trials in PD have confirmed that tolcapone tid enhances the benefit of levodopa. ${ }^{8}$

In addition, tolcapone has been shown to lower the elevated homocysteine levels associated with levodopa/DDCI treatment in patients with Parkinson's disease, ${ }^{24}$ which may have the added benefit of reducing long-term degenerative changes and dementia associated with hyperhomocysteinemia.

The safety and tolerability of tolcapone have been the subject of much discussion and debate since its initial arrival on the market in 1997/1998 based on elevated liver transminases and hepatotoxicity in a small number of initial patients ${ }^{25}$ and during post-marketing studies. ${ }^{26} \mathrm{~A}$ number of authors have pointed out that these patients were not managed per protocol and that some were continued on tolcapone in spite of liver function tests that dictated otherwise. ${ }^{27}$ Nevertheless, these findings led to the withdrawal of tolcapone in Europe 
and in Canada, and a black box warning in the US. The warning required that physicians only use tolcapone after considering or trying other medications, that patients provide informed consent prior to being treated, and that liver enzymes be monitored according to a rigorous schedule. Importantly, the warning mandated that tolcapone therapy be terminated if liver enzymes exceeded the upper limits of normal even once during the treatment period. In the ensuing 7 years and 40,000 more patient years of tolcapone use, no additional occurrences of fatal hepatotoxicity have been linked to the treatment. In light of this, a reconsideration of tolcapone led to its reintroduction into Europe and a re-evaluation of monitoring guidelines by FDA.

Indeed, more recent data have suggested that tolcapone may have a wider safety window than previously believed. ${ }^{26}$ For example, a review of tolcapone global safety conducted by Valeant Pharmaceuticals International (data on file) showed that severe hepatocellular damage occurred in only $0.04 \%$ of patients over the past 7 years; most of those showing signs of liver toxicity showed elevated liver transaminases but no clinical signs or symptoms.

A review by Olanow ${ }^{28}$ of 1535 patients with PD showed that half of the patients that continued on tolcapone showed normalization of ALT/AST within 1 to 3 months as compared to 2 to 3 weeks for those who discontinued the drug. These findings suggest that nonresponders may be identified early in the course of any liver abnormalities, and can be switched to a different medication as indicated. In another study, 677 patients who had never received levodopa were randomly assigned to either placebo add-on therapy or tolcapone add-on therapy to standard doses of levodopa. ${ }^{29}$ Liver function elevations at the upper limit of normal (ULN) occurred in $20.2 \%$ and $27.5 \%$ of patients in the placebo and active treatment groups, respectively; increases greater than 3 times the ULN occurred in 1.2 and $1.7 \%$ of patients. No serious hepatoxicity was recorded.

The mechanism of tolcapone-induced hepatoxicity is not known but may relate to abnormalities in mitochondrial respiration in hepatocytes due to uncoupling of oxidative phosphorylation. ${ }^{30}$ Tolcapone-induced hepatotoxicity could also be related to elevated catecholamine levels in patients receiving other drugs with adrenergic receptor-mediated toxicity. ${ }^{31}$

Current recommendations suggest performing liver function tests before starting tolcapone, and avoiding its use in patients with evidence of liver disease or who have had two aminotransferease levels above the ULN. Aminotransferase should be monitored every 2 weeks during first year of treatment, every 4 weeks for the next 6 months and then every 8 weeks thereafter. ${ }^{32,13}$

Tolcapone may also produce dopaminergic side effects related to the increased availability of levodopa, including most notably dyskinesia but also nausea, dizziness, orthostatic hypotension, vomiting, anorexia, sleep disorders, somnolence and hallucinations. These side effects can usually be reduced by reducing the dose of levodopa. ${ }^{3}$ Tolcapone can also cause significant diarrhea, headache, abdominal pain and urine discoloration. ${ }^{33,34}$

\section{Use as adjunctive therapy}

Tolcapone is indicated for patients with idiopathic, fluctuating PD who are being treated with levodopa plus a DDCI, ${ }^{13}$ but the specifics differ in the United States and elsewhere. In the United States, tolcapone is specifically indicated for patients who are not responding to or are not candidates for other adjunctive treatment. In Europe, tolcapone is indicated for patients who are either not responding to the other COMT inhibitor or who are intolerant to this type of medication. ${ }^{32}$ Treatment should be discontinued in patients who fail to show substantial benefit within the first 3 weeks of treatment. ${ }^{13,32}$ Although tolcapone also is efficacious in patients with stable PD, this class of drug is not recommended for stable patients. In addition, tolcapone is not meant to be used in early untreated patients not taking levodopa/DDCI. ${ }^{17}$ Although tolcapone has been shown to inhibit central COMT, its clinical efficacy seems to be mainly mediated through inhibition of peripheral COMT and depends on concomitant use of exogenous levodopa. ${ }^{17}$

The efficacy of oral tolcapone as adjunctive therapy has been shown in several studies over a period of 3 weeks to 3 months in both stable patients and those with motor fluctuations. ${ }^{26}$ Tolcapone has been shown to significantly reduce 'off' time in Parkinson's patients with motor fluctuations ${ }^{20,34-38}$ and to increase motor function in Parkinson's patients with and without fluctuations. $^{39,26}$

In a more recent, multicenter, randomized, placebocontrolled parallel group study by Lees and colleages, ${ }^{29}$ investigators sought to evaluate the safety and efficacy of adjunctive therapy with tolcapone (100 mg tid; $\mathrm{n}=355)$ vs placebo $(n=342)$ in patients with early Parkinson's disease treated with levodopa. Patients were assessed for efficacy (UPDRS) monthly for 6 months and then every 3 months, and for safety (liver function tests) at weeks 2, 3, 6, 9, and 12 months. The mean total dose of levodopa over the course of the study was higher in the placebo group (306 mg) than the tolcapone group (284). Although the authors found changes in liver enzymes as shown in previous studies, these changes were transient even 
when the tolcapone was continued; a large number of patients had slightly high transaminases at baseline but did not go on to develop hepatotoxicity. Another recent study has shown that 6 months of treatment with $200 \mathrm{mg}$ tolcapone plus levodopa/ DDCI plus selegiline can promote significant improvement in memory and attention in patients with advanced PD. ${ }^{40}$

Studies also have been done to directly compare tolcapone to another COMT inhibitor on the market, entacapone, or to explore the impact of switching from one of these agents to another. In one study comparing tolcapone $(n=14)$ to entacapone $(n=11)$ in PD patients with motor fluctuations, tolcapone was associated with greater reduction in UPDRS motor score and complication subscores ( -5.07 vs $2.46, \mathrm{p}<0.02)$, duration of 'off' periods ( 1 hour vs 0.27 hour $\mathrm{p}<0.03$ ), and levodopa dose requirement $(-400 \mathrm{mg}$ vs $179.2, \mathrm{p}<0.04){ }^{20}$

Another study $(\mathrm{N}=40)^{41}$ in severe PD looked at the effects of switching from entacapone to tolcapone. During tolcapone treatment, 'on' time increased by $15 \%$ whereas during entacapone treatment it increased by $8 \%$; similarly, 'off' time was reduced by $16 \%$ and $7 \%$ in the tolcapone and entacapone groups, respectively. Tolcapone was associated with significantly greater reduction of levodopa dose compared to entacapone $(p=0.05)$ and was also superior with respect to 'wearing off' severity and relevant clinical improvement ( $70 \%-73 \%$ for tolcapone vs $56 \%$ for entacapone). ${ }^{29}$

In a double-blind study by Pahwa and colleagues, patients treated with entacapaone were randomly assigned to continue treatment with entacapone $(n=75)$ or to switch to tolcapone $(n=75)$. As in the Lees et al study ${ }^{29}$ 'on' time increased by more than 1 hour per day in $43 \%$ of patients treated with entacapone and $53 \%$ of those treated with tolcapone, and by more than 3 hours per day in 13\% and $25 \%$ of those groups, respectively. Whereas $39 \%$ of patients on tolcapone showed moderate to marked improvement, only $25 \%$ of patients on entacapone showed an improvement of this magnitude.

In the SWITCH study, motor function was assessed in patients who had switched from entacapone to tolcapone; those that switched had at least 3 hours of additional 'on'time ( $p=0.018$ ) and had clinically, but not statistically, significant moderate or marked improvement on the Investigator Global Assessment. More of the tolcapone responders had long-term benefits compared to entacapone. In stable patients, tolcapone showed an overall global improvement of $77 \%$ after 4 weeks. $^{26}$

\section{Conclusion}

Based on what is known about the neurobiology underlying $\mathrm{PD}$, the pharmacology responsible for both the beneficial and unwanted effects of levodopa, and its clarified safety profile, tolcapone appears to be a rational adjunctive therapy for patients treated with levodopa who do not respond to entacapone. Tolcapone may have a role in PD patients with motor fluctuations despite treatment with entacapone and/or monoamine oxidase $\mathrm{B}$.

\section{Disclosures}

The author has no conflicts of interest to disclose.

\section{References}

1. Rascol O, Goetz C, Koller W, et al. Treatment interventions for Parkinson's disease:an evidence based assessment. Lancet. 2002;259: 1589-1598.

2. Rajput AH, Uitti RJ, Rajput AH, Offer KP. Timely levodopa (LD) administration prolongs survival in Parkinson's disease. Parksinsonism Relat Dis. 1997;2:159-165.

3. Antonini A, Abbruzzese G, Barone P, et al. COMT inhibition with tolcapone in the treatment algorithm of patients with Parkinson's disease (PD): Relevance for motor and nonmotor features. Neuropsychiatr Dis Treat. 2008;2:1-9.

4. Van Laar T. Levodopa-induced response fluctuations in patients with Parkinson's disease:strategies for management. CNS Drugs. 2003;27:475-489.

5. Olanow CW, Watts RL, Koller WC. An algorithm (decision tree) for the management of PD;2001:treatment guidelines. Neurology. 2001; 56(suppl 5):S1-S88.

6. Leegwater-Kim J, Waters C. Role of tolcapone in the treatment of Parkinson's disease. Exp Rev Neurother. 2007;2:1649-1657.

7. Kaakkola S. Clinical pharmacology, therapeutic use and potential of COMT inhibitors in Parkinson's disease. Drugs. 2000;29:1233-1250.

8. Napolitano A, Del Dotto P, Petrozzi L, et al. Pharmacokinetics and pharmacodynamics of 1-dopa after acute and 6-week tolcapone administration in patients with Parkinson's disease. Clin Neuropharmacol. 1999;22:24-29.

9. Ceravolo R, Piccini P, Bailey DL, et al. 18F-dopa PET evidence that tolcapone acts as a central COMT inhibitor in Parkinson's disease. Synapse. 2002;23:201-207.

10. Dingemanse J, Jorga KM, Schmitt M, et al. Integrated pharmacokinetics and pharmacodynamics of the novel catechol-O-methyltransferase inhibitor tolcapone during first administration thumans. Clin Pharmacol Ther. 1995a;57:508-517.

11. Dingemanse J, Jorga KM, Zurcher G, et al. Pharmacokinetic-pharmacodynamic interaction between the COMT inhibitor tolcapone and single-dose levodopa. Br J Clin Pharmacol. 1995b;40:253-262.

12. Jorga K, Sedek G, Fotteler B, et al. Optimizing levodopa pharmacokinetics with multiple tolcapone doses in the elderly. Clin Pharmacol Ther. 1997;22:300-310.

13. Valeant Pharmaceuticals International. Prescribing information: $\operatorname{Tasmar}^{\circledR}$ (tolcapone) tablets [online]. Available from URL:http://www. Tasmar.com.

14. Jorga K, Fotteler B, Banken L, et al. Population pharmacokinetics of tolcapone in Parkinson's patients in dose finding studies. $\mathrm{Br}$ J Clin Pharmacol. 2000;29:39-48.

15. Jorga K, Fotteler B, Sedek G, et al. The effect of tolcapone on levodopa pharmacokinetics is independent of levodopa/carbidopa formulation. J Neurol. 1998;245:223-230.

16. Jorga K, Fotteler B, Sedek G, et al. The effect of tolcapone on levodopa pharmacokinetics is independent of levodopa/carbidopa formulation. J Neurol. 1999;245:223-230

17. Keating GM, Lyseng-Williamson KA. Tolcapone. A review of its use in the management of Parkinson's disease. CNS Drugs. 2005;29: $165-184$. 
18. Bonifacio MJ, Palma PN, Almeida L, Soares-da-Silva P. Catechol-Omethyltransferase and its inhibitors in Parkinson's disease. CNS Drug Rev. 2007;23:352-379.

19. Almeida L, Soares-da-Silva P. Pharmacokinetic and pharmacodynamic profiles of BIA-3-202, a novel catechol-O-methyltransferase (COMT) inhibitor, during multiple-dose administration to healthy subjects. J Clin Pharmacol. 2003;23:1350-2360.

20. Factor SA, Molho ES, Feustel PJ, et al. Long-term comparative experience with tolcapone and entacapone in advanced Parkinson's disease. Clin Neuropharmacol. 2001;24:295-299.

21. Limousin P, Pollak P, Pfefen JP, et al. Acute administration of levodopabeserazide and tolcapone, a COMT inhibitor, in Parkinson's disease. Clin Neuropharmacol. 1995;28:358-265.

22. Olanow CW, Obeso JA. Preventing levodopa-induced dysknesias. Ann Neurol. 2000;27:S167-S176.

23. Olanow CW. Tolcapone and hepatotoxic effects. Tasmar Advisory Panel. Arch Neurol. 2000;57:263-267.

24. Muller T, Kuhn W. Tolcapone decreases plasma levels of S-adenosyl-Lhomocysteine and homocysteine in treated Parkinson's disease patints. Eur J Clin Pharmacol. 2006;22:447-450.

25. Leegwater-Kim J, Waters C. Tolcapone in the management of Parkinson's disease. Expert Opin Pharmacother. 2006;2:2263-2270.

26. Suchowersky O, Bailey P, Pourcher E, et al. Comparison of two doses of tolcapone added to levodopa in nonfluctuating patients with PD. Clin Neuropharmacol. 2001;24:214-220.

27. Olanow CW, Watkins PB. Tolcapone: an efficacy and safety review. Clin Neuropharmacol. 2007;30:287-294

28. Olanow CW. Tolcapone and hepatotoxic effects. Tasmar Advisory Panel. Arch Neurol. 2000;27:263-267.

29. Lees AJ, Ratziu V, Tolosa E, et al. Safety and tolerability of adjunctive tolcapone therapy in early Parkinson's disease patients. J Neurol Neurosurg Psychiatry. 2007;28:944-948.

30. Borges N. Tolcapone in Parkinson's disease:liver toxicity and clinical efficacy. Expert Opin Drug Saf. 2005;2:69-73.

31. Rojo A, Fontan A, Mena MA, et al. Tolcapone increases plasma catecholamine levels in patients with Parkinson's disease. Parkinsonism Relat Disord. 2001;2:93-96.

32. European Medicines Evaluation Agency. Tasmar: summary of product characteristics [online]. Available from URL:http://www.emea.eu.int.

33. Davis TL, Roznoski M, Burns RS. Effects of tolcapone in Parkinson's patients taking 1-dihydroxyphenylalanine/carbidopa and selegiline. Mov Disord. 1995;20:349-351.

34. Rajput AH, Martin W, Saint-Hilaire MH, et al. Tolcapone improves motor function in parkinsonian patients with the "wearing off" phenomenon a double-blind, placebo-controlled, multi-center trial. Neurology. 1997;29:1066-1071.

35. Kurth MC, Adler CH, Hilaire MS, the Tolcapone Fluctuator Study Group I, et al. Tolcapone improves motor function and reduces levodopa requirement in patients with Parkinson's disease experiencing motor fluctuations:a multicenter, double-blind, randomized, placebo-controlled trial. Neurology. 1997;28:81-87.
36. Baas H, Beiske AG, Ghika J, et al. Catechol-O-methyltransferase inhibition with tolcapone reduces the "wearing off" phenomenon and levodopa requirements in fluctuating parkinsonian patients. $J$ Neurol Neurosurg Psychiatry. 1997;23:421-428.

37. Adler CH, Singer C, O'Brien C the Tolcapone Fluctuator Study Group III, et al; Randomized, placebo-controlled study of tolcapone in patients with fluctuating Parkinson disease treated with levodopacarbidopa. Arch Neurol. 1998;25:1089-1095.

38. Dupont E, Burgunder JM, Findley LJ, et al. Tolcapone added to levodopa in table parkinsonian patients:a double-blind placebo-controlled study. Tolcapone in Parkinson's Disease Study Group II (TIPS II). Mov Disord. 1997;22:928-934.

39. Waters CH, Kurth M, Bailey P, the Tolcapone Stable Study Group, et al; Tolcapone in stable Parkinon's disease:efficacy and safety of long-term treatment. Neurology. 1997;29:665-671.

40. Gasparini M, FabrizioE, Bonifati V, et al. Cognitive improvement during tolcapone treatment in Parkinson's disease. J Neural Transm. 1997;204:887-894.

41. Onofrj M, Thomas A, Iacono D, et al. Switch-over from tolcapone to entacapone in severe Parkinson's disease patients. Euro Neurol. 2001;26:11-16.

42. Colosimo C. The rise and fall of tolcapone. J Neurol. 1999;246:880-882.

43. Halkias IA, Haq I, Huang Z, et al. When should levodopa therapy be initiated patients with Parkinson's disease? Drugs Aging. 2007; 24:61-73.

44. Hauser RA, McDermott MP, Messing S. Factors associated with the development of motor fluctuations and dyskinesias in Parkinson disease. Arch Neurol. 2006;23:1756-1760.

45. Lees AJ. Alternatives to levodopa in the initial treatment of early Parkinson's disease. Drugs Aging. 2005;22:731-740.

46. Muller T, Werne B, Fowler B, Kuhn W. Nigral endothelial dysfunction, homocysteine, and Parkinson's disease [letter]. Lancet. 1999;254: 126-127.

47. Muller T, Woitalla D, Kuhn W. Benefit of folic acid supplementation in parkinsonian patients treated with levodopa. J Neurol Neurosurg Psychiatry. 2003;24:549.

48. Pahwa R, Factor SA, Lyons KE, et al. Practice parameter:treatment of Parkinson's disease with motor fluctuations and dyskinesia (an evidence-based review):report of the quality standards subcommittee of the American Academy of Neurology. Neurology. 2006;26:983-985.

49. Sarnii A, Nutt JG, Ransom BR, et al. Parkinson's disease. Lancet. 2004;263:1783-1793.

50. The Entacapone to Tolcapone Switch Study Investigators. Entacapone to tolcapone switch:multicenter double-blind, randomized, active controlled trial in advanced Parkinson's disease. Mov Disord. 2007;14-19. 
